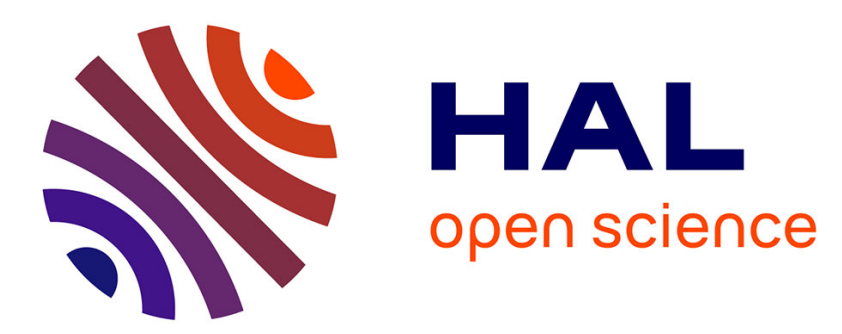

\title{
Experimental and kinetic modelling study of the oxidation of cyclopentane and methylcyclopentane at atmospheric pressure
}

\author{
G. Dayma, S. Thion, Z. Serinyel, P. Dagaut
}

\section{To cite this version:}

G. Dayma, S. Thion, Z. Serinyel, P. Dagaut. Experimental and kinetic modelling study of the oxidation of cyclopentane and methylcyclopentane at atmospheric pressure. International Journal of Chemical Kinetics, 2020, 52 (12), pp.943-956. 10.1002/kin.21412 . hal-02934478

HAL Id: hal-02934478

https://hal.science/hal-02934478

Submitted on 9 Sep 2020

HAL is a multi-disciplinary open access archive for the deposit and dissemination of scientific research documents, whether they are published or not. The documents may come from teaching and research institutions in France or abroad, or from public or private research centers.
L'archive ouverte pluridisciplinaire HAL, est destinée au dépôt et à la diffusion de documents scientifiques de niveau recherche, publiés ou non, émanant des établissements d'enseignement et de recherche français ou étrangers, des laboratoires publics ou privés.

$$
\text { Copyright }
$$




\title{
Experimental and kinetic modelling study of the oxidation of cyclopentane and methylcyclopentane at atmospheric pressure
}

\author{
G. Dayma ${ }^{1,2}$, S. Thion ${ }^{2}$, Z. Serinyel ${ }^{1,2}$, and P. Dagaut ${ }^{2}$ \\ ${ }^{1}$ UFR Sciences et Techniques, Université d'Orléans, rue de Chartres, 45100 Orléans \\ ${ }^{2}$ CNRS-ICARE, 1C avenue de la Recherche Scientifique, 45071 Orléans cedex 1
}

Corresponding author: guillaume.dayma@cnrs-orleans.fr

\begin{abstract}
Cyclopentane and methylcyclopentane oxidation was investigated in a jet-stirred reactor at atmospheric pressure, over temperatures ranging from $900 \mathrm{~K}$ to $1250 \mathrm{~K}$, for fuel-lean, stoichiometric, and fuel-rich mixtures at a constant residence time of $70 \mathrm{~ms}$. The initial mole fraction of both fuels was kept constant at $1000 \mathrm{ppm}$. The reactants were highly diluted by a flow of nitrogen to ensure thermal homogeneity. Samples of the reacting mixture were analyzed on-line and off-line by Fourier transform infrared spectroscopy and gas chromatography. A detailed kinetic mechanism consisting of 590 species involved in 3469 reactions was developed and simulation results were compared to these new experimental data and previously reported ignition delays. Reaction pathways analysis as well as sensitivity analyses were performed to get insights into the differences observed during the oxidation process of cyclopentane and methylcyclopentane.
\end{abstract}

\section{Introduction}

As compared to linear alkanes, the oxidation of cyclo-alkanes and substituted cycloalkanes, such as cyclo-pentane and methylcyclopentane, has received very little attention. However, with the growing interest on biomass-derived fuels, and fuels derived from oil sands and shale, the understanding of the combustion chemistry of these cyclic hydrocarbons becomes of major scientific and practical importance. Among cycloalkanes, cyclohexane is the most studied one. In their work on the low- and high-temperature oxidation of cyclohexane, Serinyel et al. ${ }^{1}$ reported more than 20 previous studies on this compound. They also validated a detailed kinetic mechanism for the oxidation of cyclohexane under jet-stirred reactor conditions as well as laminar burning velocities and ignition delays in shock-tube and rapid compression machine. Furthermore, the combustion community has also shown interest to alkylated cyclohexanes, from methyl to propyl, under various experimental conditions. Despite recent attention, studies on cyclopentane or methylcyclopentane oxidation are still scarse.

Tsang ${ }^{2}$ investigated the thermal decomposition of cyclopentane using a single-pulse shock tube. Several distinct pathways were considered and the isomerization to 1-pentene was found to be a major route of consumption under these conditions, while the formation of cyclopropane was also detected. High-temperature autoignition of cyclopentane was studied by Sirjean et al. ${ }^{3}$ in a shock tube. A detailed chemical kinetic mechanism was developed and used to explain the longer ignition delays observed as compared to cyclohexane. The ring opening of cyclopentyl radicals was demonstrated to be responsible for this lower reactivity. Cyclopentane ignition was also investigated at elevated pressures by Daley et al. ${ }^{4}$ and compared to that of cyclohexane. Mechanisms from the literature were tested and, although the general trends were captured, they all predicted ignition times generally longer than those measured. Recently, AlRashidi et al. ${ }^{5-7}$ elucidated the different reactivity regimes in cyclopentane oxidation by means of jet-stirred reactor experiments, computational chemistry, and kinetic modelling. Their simulations reproduced the unique reactivity trend of cyclopentane at high-pressure and they showed that this peculiar behavior may be attributed to the $\mathrm{C}-\mathrm{C} / \mathrm{C}-\mathrm{H}$ scission branching ratio of the cyclopentyl radical. 
The oxidation of methylcyclopentane was first studied by Burgoyne and Silk ${ }^{8}$ in a quartz bulb. They determined the pressure-temperature limits for spontaneous cool- and hot-flame ignitions of methylcyclopentane-oxygen mixtures. Brown and King ${ }^{9}$ investigated the very-lowpressure pyrolysis of methylcyclopentane. The data were interpreted in terms of ring-opening bond fission pathways and bond fission to methyl and cyclo-alkyl radicals. They proposed highpressure rate expressions for the overall decomposition of methylcyclopentane and showed their data supported the assumption of a biradical mechanism for ring opening. More recently, Sivaramakrishnan and Michael ${ }^{10}$ measured the high-temperature rate constants of methylcyclopentane $\mathrm{H}$-abstractions by $\mathrm{OH}$ radicals in a shock tube and showed that these reactions are favored on ortho secondary carbons (carbon s1 in Fig. 1). Sirjean et al. ${ }^{11}$ theoretically studied the thermal unimolecular decomposition of methylcyclopentyl radicals. For ring-opening reactions, they showed an increase of the activation energy when the double bond is formed in the ring (endo) in contrast to the cases in which the double bond is formed on the side chain (exo). Boehman and coworkers ${ }^{12-14}$ focused on the low-temperature oxidation of cycloalkanes in engines. They observed methylcyclopentane showed little low-temperature reactivity prior to autoignition as compared to methylcyclohexane or decalin. Moreover, methylcyclopentenes were found to play an important role under their conditions, and methyl substitution on the ring was found to significantly promote the formation of propene relative to ethylene. Tian et al. ${ }^{15}$ measured ignition delay times of cyclopentane $/ \mathrm{O}_{2}$ and methylcyclopentane $/ \mathrm{O}_{2}$ mixtures diluted in argon and developed a detailed kinetic mechanism validated against their experimental results. They observed methylcyclopentane had shorter ignition delays than cyclopentane and attributed this to the presence of the methyl group and the propensity of methylcyclopentane to produce $\mathrm{H}$ atoms. Finally, Fridlyand et al. ${ }^{16}$ explored the low-temperature reactivity of cyclopentane, methylcyclopentane, and ethylcyclopentane under stoichiometric conditions at 20 and 50 bar in a rapid-compression machine. They observed ethylcyclopentane was the most reactive whereas cyclopentane exhibited a limited reactivity under these conditions, methylcyclopentane being in between.

In addition to the results available in the literature, the purpose of this work is to obtain new experimental data on cyclopentane and methylcyclopentane oxidation in order to further validate a detailed kinetic mechanism. Once validated, this mechanism will be used to delineate the different reactivity of cyclopentane and methylcyclopentane.

\section{Experimental Section}

The JSR experimental setup has been described in previous studies ${ }^{17,18}$. Briefly, it consists of a $4 \mathrm{~cm}$ diameter fused silica sphere with four $1 \mathrm{~mm}$ i.d. nozzles. High purity nitrogen $(<100$ ppm $\mathrm{H}_{2} \mathrm{O},<50$ ppm $\mathrm{O}_{2},<1000 \mathrm{ppm} \mathrm{Ar},<5 \mathrm{ppm} \mathrm{H}_{2}$, Air Liquide) was used as a diluent and mixed with the reactants before reaching the mixing point at the entrance of the injectors. High dilution $(0.1 \% \mathrm{~mol}$. of fuel) was used to reduce temperature gradients and heat release inside the reactor. High-purity reactants were used: oxygen $99.995 \%$ pure was provided by Air Liquide, while cyclopentane (CAS 287-92-3) > $98 \%$ pure and methylcyclopentane (CAS 96$37-7)>97 \%$ pure were both obtained from Aldrich. $1.2 \%$ of n-pentane was measured within cyclopentane and $0.7 \%$ of $n$-hexane within methylcyclopentane. These impurities were taken into account for the simulations. To reduce temperature gradients inside the reactor, the reactants were preheated before injection. The fuel was delivered to a vaporizer assembly maintained at $473 \mathrm{~K}$ by means of a HPLC pump and an online degassing unit (Shimadzu LC10 $\mathrm{AD}$ VP and DGU-20 A3). Small temperature gradients $(\sim 1 \mathrm{~K} / \mathrm{cm})$ were measured along the vertical axis of the reactor using a thermocouple located inside a thin-wall fused-silica tube $(0.1$ $\mathrm{mm} \mathrm{Pt}-\mathrm{Pt} / \mathrm{Rh}-10 \%$ ) to prevent catalytic reactions on the metallic wires. A fused-silica lowpressure sonic probe was used to sample the reacting mixtures and send samples to the analyzers via a Teflon heated line (393 K). Gas samples were analyzed online by FTIR. A resolution of 
$0.5 \mathrm{~cm}^{-1}$ was used. The sample cell had a $10 \mathrm{~m}$ optical path length and samples were analyzed at 200 mbar. Off-line GC analyses following collection and storage at $\sim 50$ mbar in 1L Pyrex bulbs were also performed. Gas chromatographs operating with capillary columns (a $0.32 \mathrm{~mm}$ i.d. DB-624, a $0.32 \mathrm{~mm}$ i.d. $\mathrm{CP}-\mathrm{Al}_{2} \mathrm{O}_{3}-\mathrm{KCl}$, a $0.53 \mathrm{~mm}$ i.d. CP-Carboplot-P7, and a $0.32 \mathrm{~mm}$ i.d. CP-SIL 5CB coupled to a $0.53 \mathrm{~mm}$ i.d. DB1-ms), a TCD (thermal conductivity detector), and a FID (flame ionization detector). Two GC-MS (Varian CP3800-V1200 and Shimadzu GCMS 2010 Plus) operating with electron impact ionization $(70 \mathrm{eV})$ were used for products identification. Thanks to this analytical equipment, it was possible to measure several species with different techniques or columns, giving high confidence into our measurements. The measured species were: $\mathrm{CO}, \mathrm{CO}_{2}$, water, $\mathrm{H}_{2}, \mathrm{O}_{2}$, methane, formaldehyde, ethane, ethylene, acetylene, propene, allene, propyne, acroleine, 1-butene, 1,3-butadiene, vinylacetylene, 1pentene, 1-hexene, benzene, cyclopentene, cyclopentadiene, methylcyclopentene, methylcyclopentadiene, 1,3-cyclohexadiene, cyclopentane and methylcyclopentane.

All the experiments were performed at a mean residence time, $\tau$, of $70 \mathrm{~ms}$ and a pressure of $1 \mathrm{~atm}$. The reactants were constantly flowing into the JSR, while the reactor temperature was increased stepwise from 900 to $1250 \mathrm{~K}$. A good repeatability of the measurements and a reasonably good carbon balance (typically $100 \pm 15 \%$ ) were obtained.

\section{Kinetic Modeling}

The kinetic mechanism developed by Tian et al. ${ }^{15}$ was tested against our new experimental results and was found to be too reactive (see Figure S1 in the Supplementary Material). Therefore, a detailed kinetic reaction mechanism was developed based on a previously published mechanism for the oxidation of a variety of fuels up to $\mathrm{C}_{6}{ }^{19,20}$. It was extended by including the chemistry of cyclopentane and methylcyclopentane oxidation. Cyclopentene, cyclopentadiene, hex-1-ene and hex-2-ene sub-mechanisms were also revisited to improve our predictions. For the new species, the thermochemical properties were computed using group and bond additivity methods ${ }^{21}$. The kinetic modelling of cyclopentane and methylcyclopentane oxidation in jet-stirred reactor was performed using the PSR computer code ${ }^{22}$ while ignition delays were computed thanks to the SENKIN code ${ }^{23}$, both from the CHEMKIN-II package. The detailed kinetic reaction mechanism consisting of 590 species involved in 3469 reactions and the thermochemical properties are provided as Supplementary Material. Figure 1 shows the molecular structure of cyclopentane and methylcyclopentane with carbon atoms labeled as in the mechanism. The chemical structure, the name used in the mechanism as well as the heat of formation and entropy at $298 \mathrm{~K}$ of the most important species in $\mathrm{C}_{5}$ cyclic species submechanism are gathered in Table 1.

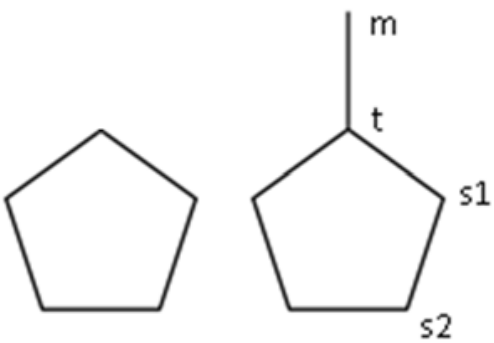

Figure 1: Cyclopentane (left) and methylcyclopentane (right) with carbon labels.

The fuel (either cyclopentane or methylcyclopentane) can react via thermal decomposition involving $\mathrm{C}-\mathrm{C}$, and $\mathrm{C}-\mathrm{H}$ bond breaking. Previous it was shown that ring opening for cycloalkanes proceeds through the formation of biradical intermediates ${ }^{24-26}$. In the case of methylcyclopentane, homolytic $\mathrm{C}-\mathrm{C}$ bond scissions yield 1-hexene, 2-hexene, or three different 
methylpentene isomers, whereas for cyclopentane either 1-pentene or propene and ethylene can be produced.

Table 1: Chemical structures, names used in the kinetic mechanism, and heat of formation $(\mathrm{kcal} / \mathrm{mol})$ and entropy $(\mathrm{cal} / \mathrm{K} / \mathrm{mol})$ at $298 \mathrm{~K}$ of the most important species in cyclopentane and methylcyclopentane sub-mechanisms.

\begin{tabular}{|c|c|c|c|c|}
\hline $\begin{array}{c}\text { cyc5h10 } \\
\Delta_{\mathrm{f}} \mathrm{H}^{\circ}=-18.4 \\
\mathrm{~S}^{\circ}=70.0\end{array}$ & $\begin{array}{c}\text { cyc5h9 } \\
\Delta_{\mathrm{f}} \mathrm{H}^{\circ}=26.6 \\
\mathrm{~S}^{\circ}=71.4\end{array}$ & $\begin{array}{c}c y c 5 h 8 \\
\Delta_{\mathrm{f}} \mathrm{H}^{\circ}=8.9 \\
\mathrm{~S}^{\circ}=68.1\end{array}$ & $\begin{array}{c}\text { cyc5h7 } \\
\Delta_{\mathrm{f}} \mathrm{H}^{\circ}=41.3 \\
\mathrm{~S}^{\circ}=70.8\end{array}$ & $\begin{array}{c}c p d \\
\Delta_{\mathrm{f}} \mathrm{H}^{\circ}=24.2 \\
\mathrm{~S}^{\circ}=65.5\end{array}$ \\
\hline $\begin{array}{c}\text { mcp } \\
\Delta_{\mathrm{f}} \mathrm{H}^{\circ}=-25.6 \\
\mathrm{~S}^{\circ}=81.1\end{array}$ & $\begin{array}{c}\text { mcpm } \\
\Delta_{\mathrm{f}} \mathrm{H}^{\circ}=22.5 \\
\mathrm{~S}^{\circ}=83.3\end{array}$ & $\begin{array}{c}\text { mcpt } \\
\Delta_{\mathrm{f}} \mathrm{H}^{\circ}=17.9 \\
\mathrm{~S}^{\circ}=82.9\end{array}$ & $\begin{array}{c}\text { mcps1 } \\
\Delta_{\mathrm{f}} \mathrm{H}^{\circ}=20.4 \\
\mathrm{~S}^{\circ}=83.8\end{array}$ & $\begin{array}{c}\Delta_{\mathrm{f}} \mathrm{H}^{\circ}=20.4 \\
\mathrm{~S}^{\circ}=83.8\end{array}$ \\
\hline $\begin{array}{c}\text { c6h12-1 } \\
\Delta_{\mathrm{f}} \mathrm{H}^{\circ}=-10.1 \\
\Delta \mathrm{S}^{\circ}=91.6\end{array}$ & $\begin{array}{c}c 6 h 1116 \\
\Delta_{\mathrm{f}} \mathrm{H}^{\circ}=38.7 \\
\Delta \mathrm{S}^{\circ}=93.6\end{array}$ & $\begin{array}{c}\text { c6h1113 } \\
\Delta_{\mathrm{f}} \mathrm{H}^{\circ}=21.4 \\
\Delta \mathrm{S}^{\circ}=90.2\end{array}$ & $\begin{array}{c}\mathrm{c} 6 \mathrm{~h} 1115 \\
\Delta_{\mathrm{f}} \mathrm{H}^{\circ}=36.5 \\
\Delta \mathrm{S}^{\circ}=93.8\end{array}$ & $\begin{array}{c}\text { c6h1126 } \\
\Delta_{\mathrm{f}} \mathrm{H}^{\circ}=38.8 \\
\Delta \mathrm{S}^{\circ}=92.8\end{array}$ \\
\hline $\begin{array}{c}\text { c6h12-2 } \\
\Delta_{\mathrm{f}} \mathrm{H}^{\circ}=-12.8 \\
\mathrm{~S}^{\circ}=90.7\end{array}$ & $\begin{array}{c}\text { pent } 2 \mathrm{~m} 1 \mathrm{~d} 5 \\
\Delta_{\mathrm{f}} \mathrm{H}^{\circ}=35.4 \\
\mathrm{~S}^{\circ}=92.5\end{array}$ & $\begin{array}{c}\text { pent } 3 \mathrm{~m} 1 \mathrm{~d} 5 \\
\Delta_{\mathrm{f}} \mathrm{H}^{\circ}=37.6 \\
\mathrm{~S}^{\circ}=92.7\end{array}$ & $\begin{array}{c}\text { pent } 4 \mathrm{~m} 1 \mathrm{~d} 5 \\
\Delta_{\mathrm{f}} \mathrm{H}^{\circ}=36.4 \\
\mathrm{~S}^{\circ}=91.7\end{array}$ & $\begin{array}{c}c 5 \mathrm{~h} 5 \\
\Delta_{\mathrm{f}} \mathrm{H}^{\circ}=63.1 \\
\mathrm{~S}^{\circ}=64.0\end{array}$ \\
\hline
\end{tabular}

In the literature ${ }^{2,24}$, this last pathway produces cyclopropane and ethylene, but taking into account that cyclopropane was not considered in our mechanism and that, at $1000 \mathrm{~K}$, this pathway is more than 100 times slower than that yielding 1-pentene, propene replaced cyclopropane. Rate constants for both of these pathways were taken from ${ }^{2}$. For methylcyclopentane, hexenes or methylpentenes can be produced through five distinct pathways in addition to cyclopentyl and methyl radicals. The rate constants of the formation of alkenes was adapted from Tsang ${ }^{2}$ while that of the formation of cyclopentyl and methyl radicals was taken from Zhang et al. ${ }^{26}$ from methylcyclohexane decomposition. The rate constant of $\mathrm{C}-\mathrm{H}$ bond breaking leading to cyclopentyl was adopted from Al-Rashidi et al. ${ }^{5}$ while the formation of the four primary radicals of methylcyclopentane was taken from Tian et al. ${ }^{15}$. Cyclopentane may react through bimolecular initiation with $\mathrm{O}_{2}$, the rate constant of which was taken from Al-Rashidi et al. ${ }^{5}$. Methylcyclopentane may also react through bimolecular initiations with $\mathrm{O}_{2}$, yielding the four primary radicals, where rate constants used by Tian et al. 15 were adopted. Propagation reactions proceed via $\mathrm{H}$-abstraction reactions by small radicals $\left(\mathrm{H}, \mathrm{O}, \mathrm{OH}, \mathrm{HO}_{2}, \mathrm{CH}_{3}\right)$.

For cyclopentane, rate constants of $\mathrm{H}$-abstraction reactions were adopted as follows:

- by $\mathrm{OH}$ radicals from Sivaramakrishnan and Michael ${ }^{10}$

- by $\mathrm{H}$ atoms and $\mathrm{HO}_{2}$ radicals from Handford-Styring and Walker 27,28

- by $\mathrm{O}$ and $\mathrm{CH}_{3}$ radicals, no direct measurements or calculations were available and rate constants used in Dayma et al. ${ }^{29}$ were chosen. 
For methylcyclopentane, $\mathrm{H}$-abstraction reactions were adopted as follows:

- by $\mathrm{H}$ atoms, from Sivaramakrishnan et al. ${ }^{30}$ on the methyl group, from Buda et al. ${ }^{31}$ for the tertiary site, and Handford-Styring and Walker ${ }^{28}$ for the secondary sites

- by $\mathrm{OH}$ radicals, adopted from Sivaramakrishnan and Michael ${ }^{10}$ who measured and calculated these rates over a large temperature range

- by $\mathrm{HO}_{2}$ radicals on the four secondary carbons taken equal to that of cyclopentane while in the case of the primary and the tertiary carbons ( $m$ and $t$ ), rate constants used in our previous studies ${ }^{32,33}$ were chosen

- $\quad$ by $\mathrm{O}$ and $\mathrm{CH}_{3}$ radicals, rate constants were taken from ${ }^{33}$.

Figure 2 depicts a comparison of the rate constants for $\mathrm{H}$-abstraction reactions by $\mathrm{H}, \mathrm{O}$, $\mathrm{OH}, \mathrm{HO}_{2}$, and $\mathrm{CH}_{3}$ as well as the total rate constant defined as the sum of the previous five. Each of these graphs present the total rate for the small radical considered. Although some slight differences appear between the rate constants, it can be noticed that, despite an additional carbon atom and two hydrogens for methylcyclopentane, the rate constants for the $\mathrm{H}$ abstraction reactions are very close to that of cyclopentane, and the sum of all these rate constants for cyclopentane and methylcyclopentane is thus very similar. 


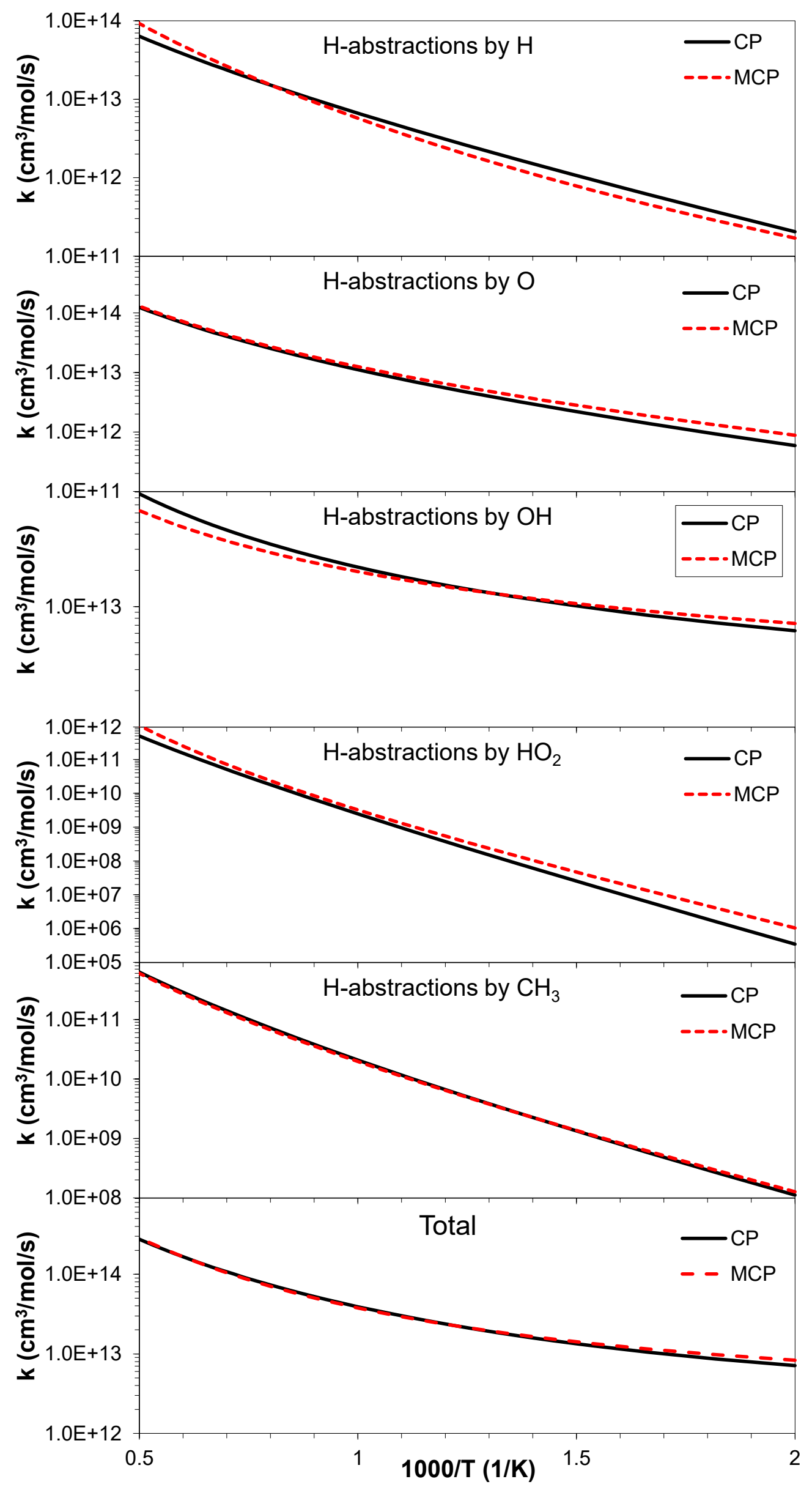


Figure 2: Evolution of the rate constants of $\mathrm{H}$-abstraction reactions by $\mathrm{H}, \mathrm{O}, \mathrm{OH}, \mathrm{HO}_{2}, \mathrm{CH}_{3}$, and total rate constant defined as the sum of the previous five for cyclopentane (full line, black) and methylcyclopentane (dashed line, red).

The decomposition reactions by $\beta$-scission of the primary radicals of both fuels were also considered. $\beta$-scission reactions involved in the consumption of cyclopentyl radicals were studied by several authors $5,11,34,35$ with significantly different results in terms of branching ratios. For most of these authors, two pathways are considered: (i) the $\mathrm{C}-\mathrm{H} \beta$-scission yielding cyclopentene from cyclopentyl (reaction $\mathrm{R} 2$ ) and (ii) the ring opening ( $\mathrm{C}-\mathrm{C} \beta$-scission) of cyclopentyl yielding pent-1-en-5-yl (reaction R1). Sun et al. ${ }^{36}$ proposed a third pathway, accounting for the prompt dissociation of pent-1-en-5-yl yielding ethylene and allyl radicals (R3). Figure 3 illustrates a comparison of the different branching ratios; in this figure, R2 and $\mathrm{R} 3$, calculated at $1 \mathrm{~atm}$, were gathered in order to compare with the $\mathrm{C}-\mathrm{H}$ and the $\mathrm{C}-\mathrm{C} \beta$-scission routes. As can be seen from this figure, for Tsang ${ }^{34}$ and Sirjean et al. ${ }^{11}$, the $\mathrm{C}-\mathrm{H} \beta$-scission pathway involving the formation of cyclopentene dominates over the temperature range of interest while for Manion and Awan ${ }^{35}$ and for Sun et al. ${ }^{36}$, the $\mathrm{C}-\mathrm{C} \beta$-scission channel (R2+R3) dominates. Intermediately, Al-Rashidi et al. ${ }^{5}$ calculated a crossover temperature (ca. $800 \mathrm{~K}$ ) above which R1 dominates. The global reactivity of cyclopentane under fuel-rich conditions and high-pressure was found to be highly sensitive to this competition between the ring opening and the $\mathrm{C}-\mathrm{H} \beta$-scission. The pressure-dependent rate constants calculated by Sun et al. ${ }^{36}$ allow to capture this behavior remarkably well (see Figure S2 in the Supplementary Material) and were thus preferred in this study.

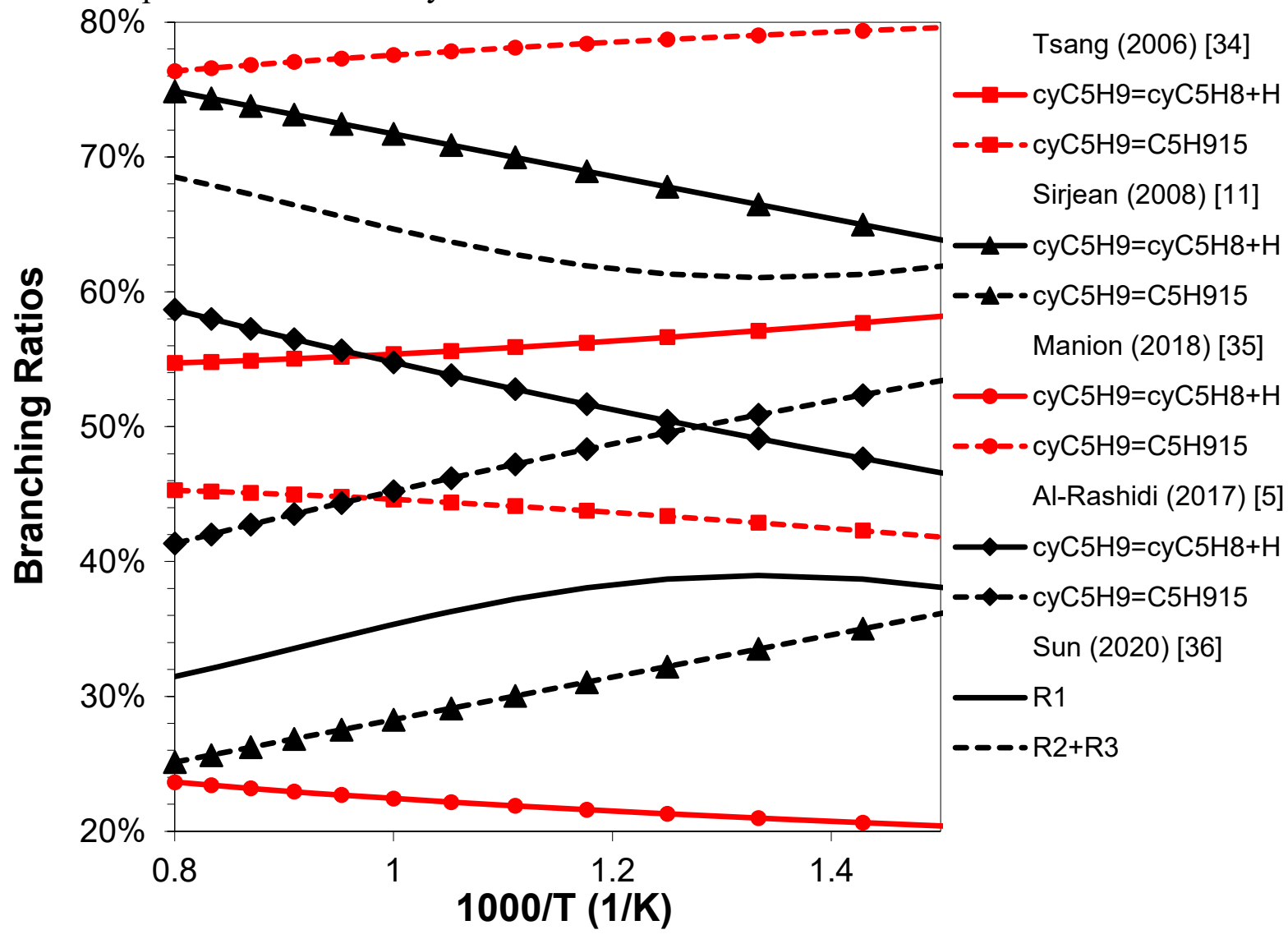

Figure 3: Comparison of the branching ratio between ring opening cyC5H9 $\rightleftharpoons \mathrm{C} 5 \mathrm{H} 915$ (R1) and hydrogen atom elimination (R2). R3 is the prompt dissociation of pent-1-en-5-yl. 
Seven different $\mathrm{C}-\mathrm{C} \beta$-scissions were considered for methylcyclopentyl radicals for which pressure-dependent rate expressions calculated by Tian et al. ${ }^{15}$ were preferred to those proposed by Sirjean et al. ${ }^{11}\left(\mathrm{k}_{\infty}\right)$. Actually, the branching ratios for the three possible $\mathrm{C}-\mathrm{C} \beta$-scissions of radical MCPs1 are quite different between these two authors as can be seen in Figure 4. Over our temperature range, both of them (rate constants were evaluated at $1 \mathrm{~atm}$ for Tian et al. ${ }^{15}$ ) predicts that the dominant channel is the formation of cyclopentene, but while for Sirjean et al. 11 this channel represents $86-94 \%$ of the total consumption of MCPs1, for Tian et al. ${ }^{15}$ it strongly decreases with the temperature increase from $82 \%$ at low temperature to $36 \%$ at high temperature. Cyclopentene is mostly produced from this radical, and the decrease of the branching ratio as the temperature increases leads to a better prediction of cyclopentene and 1,3-butadiene (produced from the other two channels), but an underprediction of cyclopentadiene, and a slight increase of the global reactivity (see Figure S3 in the Supplementary Material). Indeed, the choice is very difficult to make between these two sets considering our experimental results alone, but ignition delay times are significantly improved when rate constants from Tian et al. ${ }^{15}$ are used (see Figure S4 in the Supplementary Material).

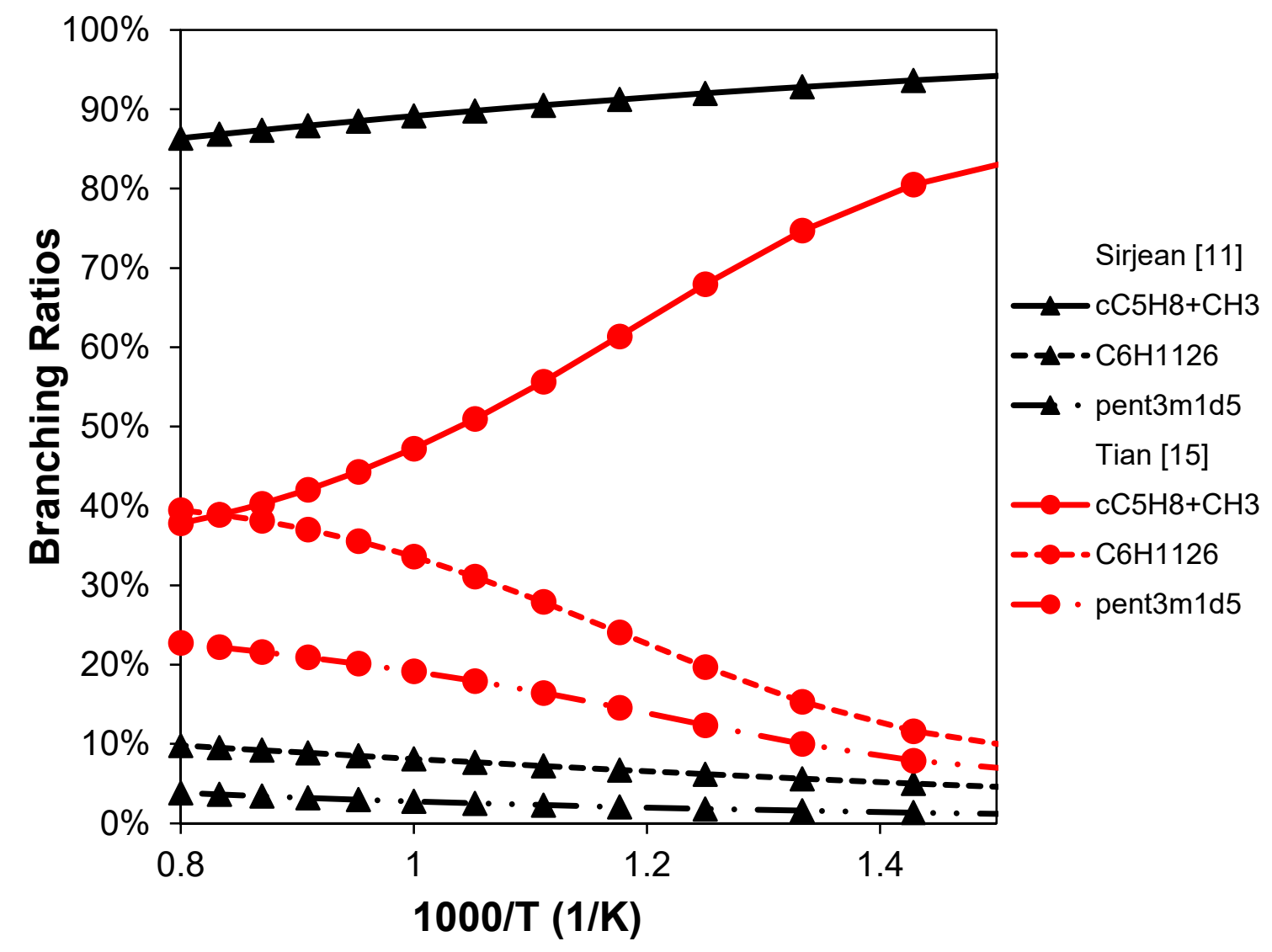

Figure 4: Comparison of the branching ratio between $\mathrm{MCPs} 1 \rightleftharpoons \mathrm{cC}_{5} \mathrm{H}_{8}+\mathrm{CH}_{3}, \mathrm{MCPs} 1 \rightleftharpoons \mathrm{C}_{6} \mathrm{H}_{11} 26$, and MCPs $1 \rightleftharpoons$ pent $3 \mathrm{~m} 1 \mathrm{~d} 5$ (rate constants evaluated at $1 \mathrm{~atm}$ for Tian et al. ${ }^{15}$ ).

For $\mathrm{C}-\mathrm{H} \beta$-scissions, rate constants used in our previous works ${ }^{32,33}$ were adopted in this study as well. For the oxidation reactions by $\mathrm{O}_{2}$ yielding cyclopentene and methylcyclopentenes or methylcyclopentadienes, the rate constants proposed by Battin-Leclerc ${ }^{37}$ were selected. Finally, the methylcyclopentadiene sub-mechanism was mostly taken from Herbinet et al. ${ }^{38}$ with the decomposition yielding methyl and cyclopentadienyl radicals coming from Sharma and Green ${ }^{39}$ at atmospheric pressure. Fulvene formation was also considered following the 
work by Jin et al. ${ }^{40}$ and Yang et al. ${ }^{41}$. Sub-mechanisms for the oxidation and pyrolysis of cyclopentene and cyclopentadiene were taken from our previous works ${ }^{20,42}$ and updated using the works by Zhong and Bozzelli ${ }^{43,44}$, Wang et al. ${ }^{45}$, Oleinikov et al. ${ }^{46}$, Ghildina et al. ${ }^{47}$ and Vermeire et al. ${ }^{48}$ on 1,5-hexadiene.

\section{Results and Discussion}

For the sake of comparison, experiments were performed at a constant mean residence time of $70 \mathrm{~ms}$ and constant atmospheric pressure for both fuels. The equivalence ratio, $\varphi$, was varied from fuel-lean to fuel-rich conditions $(0.5,1$, and 2); the fuel initial mole fraction was 1000 ppm for all experiments. The temperature ranged from 900 to $1250 \mathrm{~K}$. A good repeatability was observed in the experiments and a reasonably good carbon balance of $100 \pm 15 \%$ was achieved.

Figure 5 presents the evolution of the mole fraction of cyclopentane (CP) and methylcyclopentane $(\mathrm{MCP})$ at three different equivalence ratios $(0.5,1$, and 2$)$ together with the simulations obtained from our mechanism. It can be noticed from this figure that the conversion of cyclopentane is more affected by the equivalence ratio than that of methylcyclopentane. Half of the initial cyclopentane is consumed at $\mathrm{T}=1150 \mathrm{~K}, \mathrm{~T}=1165 \mathrm{~K}$, and $\mathrm{T}=1180 \mathrm{~K}$ for the fuel-lean, the stoichiometric and the fuel-rich mixtures respectively, while half of the initial methylcyclopentane is consumed at $\mathrm{T}=1135 \mathrm{~K}, \mathrm{~T}=1140 \mathrm{~K}$, and $\mathrm{T}=$ $1145 \mathrm{~K}$ for the fuel-lean, the stoichiometric and the fuel-rich mixtures respectively. In addition, at a given equivalence ratio, methylcyclopentane conversion occurs at lower temperatures than that of cyclopentane Thus, methylcyclopentane is slightly more reactive than cyclopentane despite a very similar $\mathrm{H}$-abstraction total rate constant (Figure 2), indicating the radical pool is more abundant in the case of methylcyclopentane oxidation than in the case of cyclopentane. Moreover, the simulations performed with our detailed kinetic mechanism are in good agreement with our experimental data for both fuels at the three equivalence ratios. 

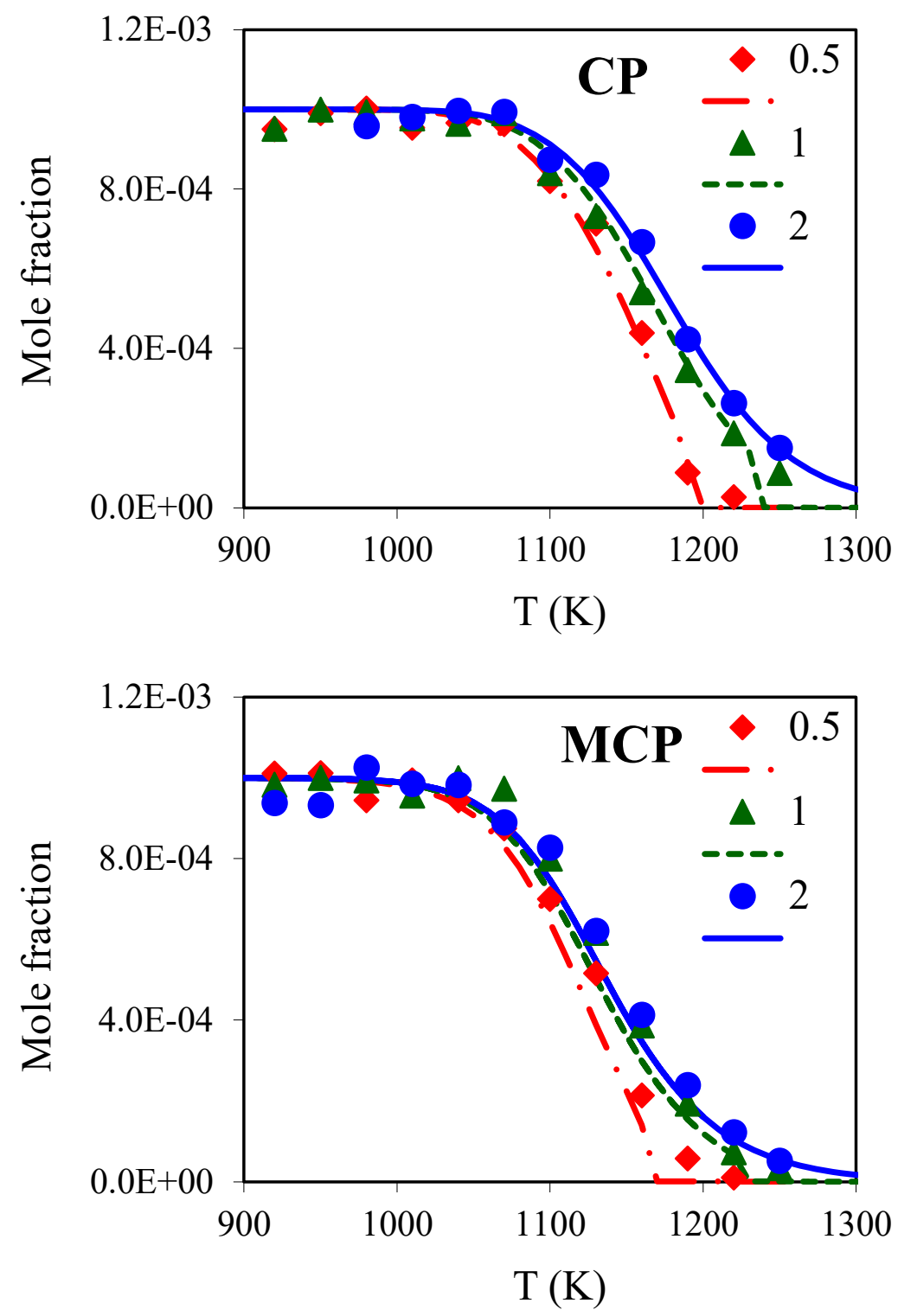

Figure 5: Experimental (symbols) and computed (lines) mole fraction profiles obtained from the oxidation of cyclopentane (CP) and methylcyclopentane (MCP) in a JSR at $p=1 \mathrm{~atm}, \tau=$ $0.07 \mathrm{~s}$, and $\varphi=0.5$ (red), $\varphi=1$ (green), and $\varphi=2$ (blue).

Figures 6-8 show the results obtained for a fuel-lean, stoichiometric, and fuel-rich mixture of cyclopentane (empty triangles-dashed line) and methylcyclopentane (filled circles-full line). Under these conditions, methylcyclopentane consumption starts at a slightly lower temperature than the conversion of cyclopentane. These experiments were indeed performed starting at 710 $\mathrm{K}$, but no evidence of reactivity below $1000 \mathrm{~K}$ was observed for both fuels under these conditions. 

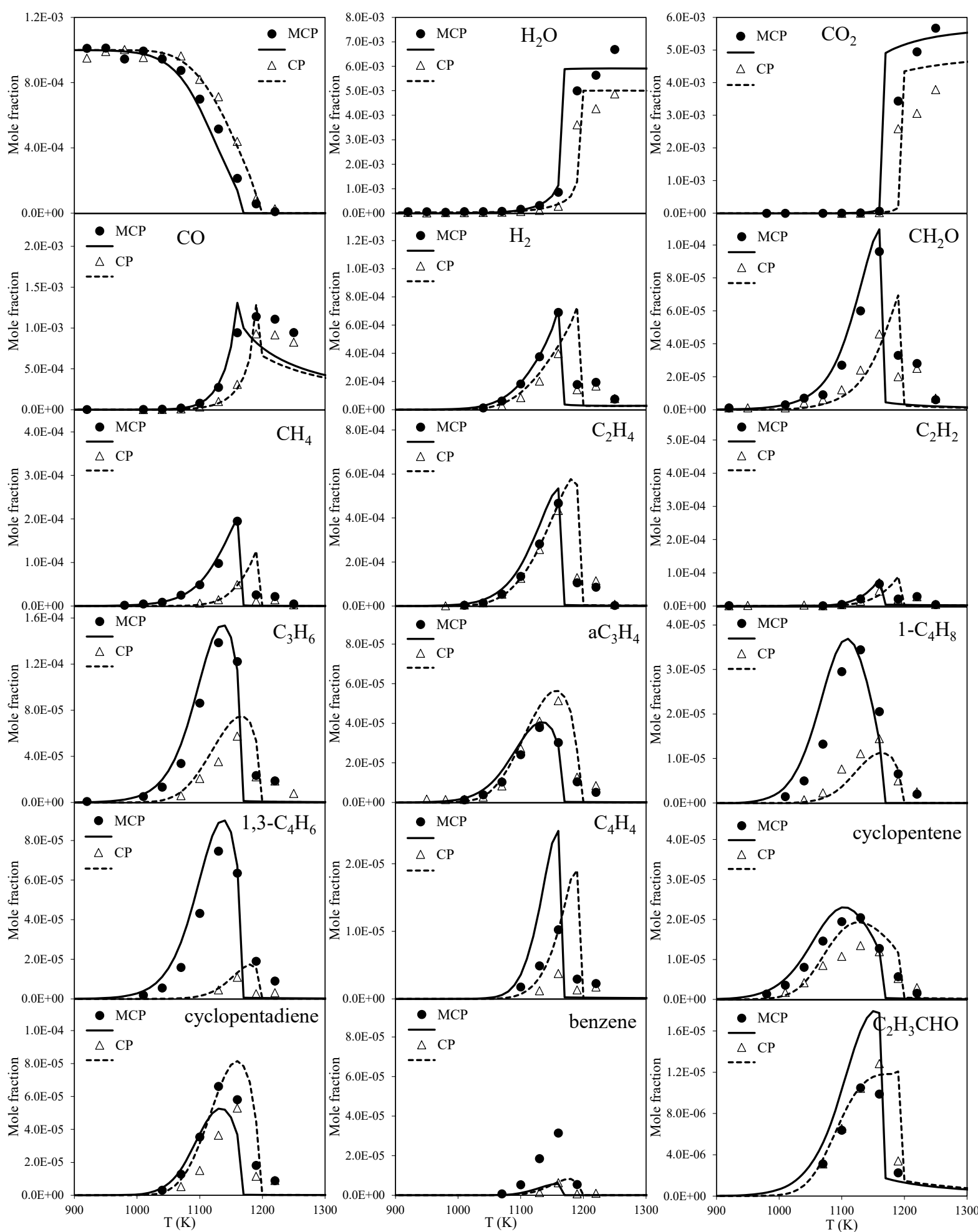

Figure 6: Experimental and computed mole fraction profiles obtained from the oxidation of cyclopentane (empty triangles-dashed line) and methylcyclopentane (filled circles-full line) in a JSR at $\varphi=0.5, p=1 \mathrm{~atm}, \tau=0.07 \mathrm{~s}$.

The observed intermediates are mainly unsaturated compounds $\left(\mathrm{C}_{2} \mathrm{H}_{2}, \mathrm{C}_{2} \mathrm{H}_{4}, \mathrm{C}_{3} \mathrm{H}_{6}, 1,3-\right.$ $\mathrm{C}_{4} \mathrm{H}_{6}$, cyclopentene, cyclopentadiene, and benzene) regardless of the equivalence ratio. Except for water, $\mathrm{CO}$, and $\mathrm{CO}_{2}$, formaldehyde and acrolein were the only oxygenated species identified. It should be noticed that $12 \mathrm{ppm}$ of n-pentane and $7 \mathrm{ppm}$ of $\mathrm{n}$-hexane were identified as impurities in cyclopentane and methylcyclopentane, respectively. This small amount of 
impurity was taken into account in our simulations but no impact was observed on the overall reactivity or the species mole fractions. Also, less than $2 \mathrm{ppm}$ of pent-1-ene and $1 \mathrm{ppm}$ of hex1-ene were measured either under fuel-lean, fuel-rich or stoichiometric conditions with cyclopentane and methylcyclopentane, respectively.
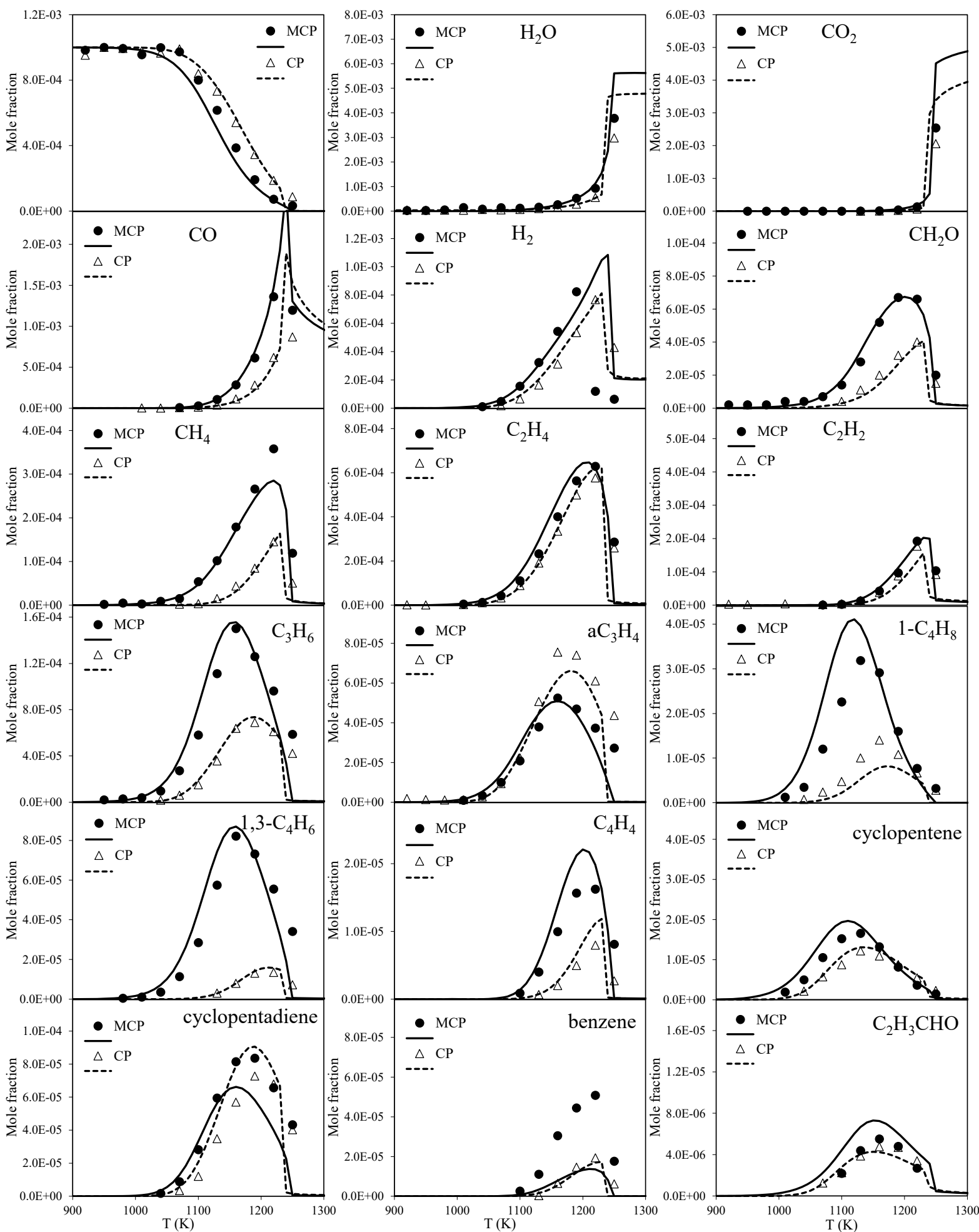

Figure 7: Experimental and computed mole fraction profiles obtained from the oxidation of cyclopentane (empty triangles and dashed line) and methylcyclopentane (filled circles and full line) in a JSR at $\varphi=1, p=1 \mathrm{~atm}, \tau=0.07 \mathrm{~s}$. 

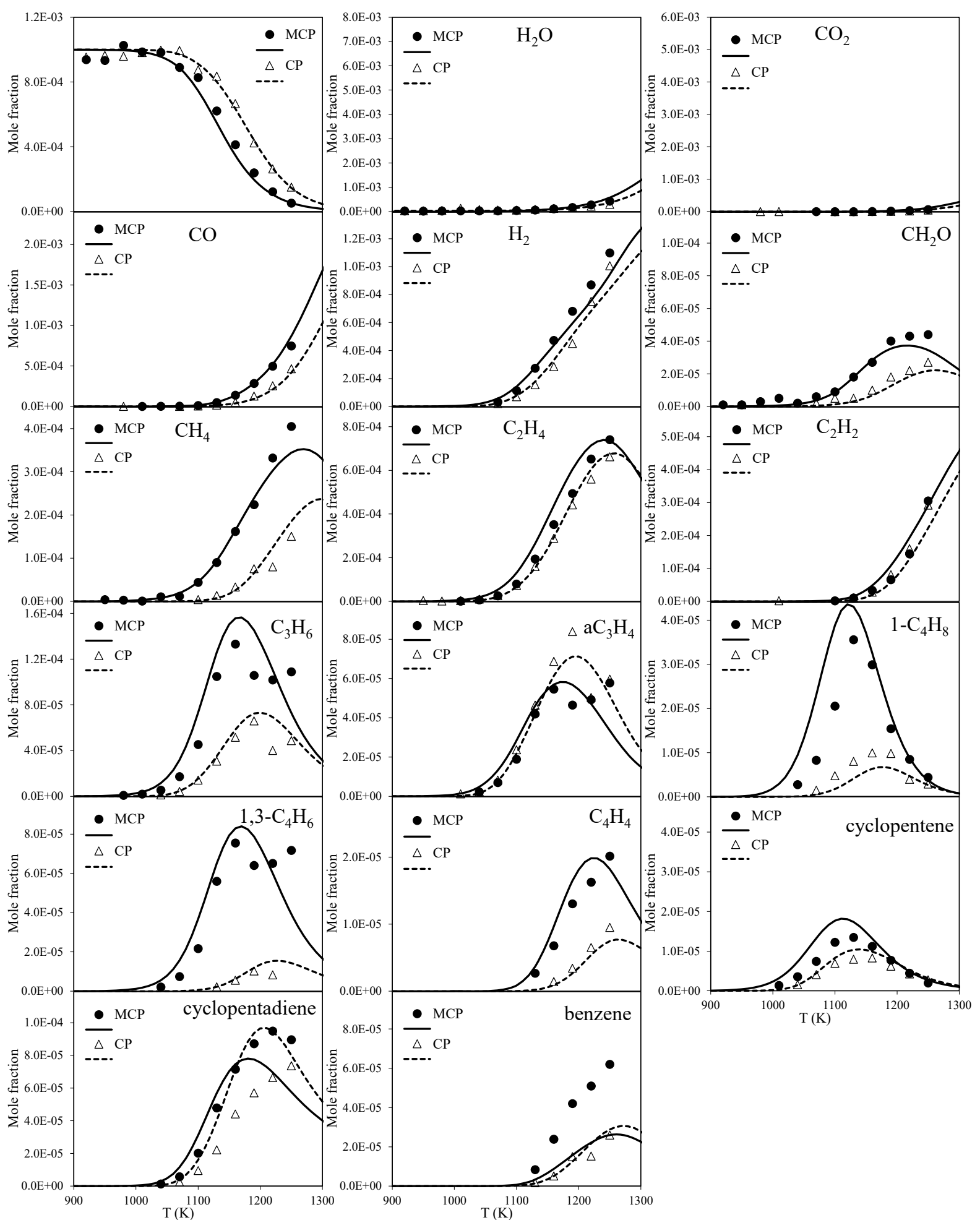

Figure 8: Experimental and computed mole fraction profiles obtained from the oxidation of cyclopentane (empty triangles and dashed line) and methylcyclopentane (filled circles and full line) in a JSR at $\varphi=2, p=1 \mathrm{~atm}, \tau=0.07 \mathrm{~s}$.

The kinetic mechanism reproduces reasonably well the experimental data. Fuel consumption is well reproduced under all the conditions investigated. Nevertheless, some discrepancies between the simulations and the experimental data can be observed for vinylacetylene $\left(\mathrm{C}_{4} \mathrm{H}_{4}\right)$, cyclopentene, or benzene, although these discrepancies are different depending on the fuel and the experimental conditions. For instance, vinylacetylene is well 
reproduced for both fuels under stoichiometric and fuel-rich conditions while it appears overestimated under fuel-lean conditions. Furthermore, although benzene is well reproduced for cyclopentane oxidation, it is patently underestimated regardless of the equivalence ratio for methylcyclopentane oxidation: Our mechanism predicts a similar amount of benzene produced by the oxidation of the two fuels whereas, experimentally, benzene accumulates twice as much for methylcyclopentane as for cyclopentane. It has to be mentioned that the mechanism developed by Tian et al. ${ }^{15}$ also strongly under estimates benzene accumulation (see Figure S5 in the Supplementary Material) indicating that pathways are probably missing or some rate constants need to be reevaluated.
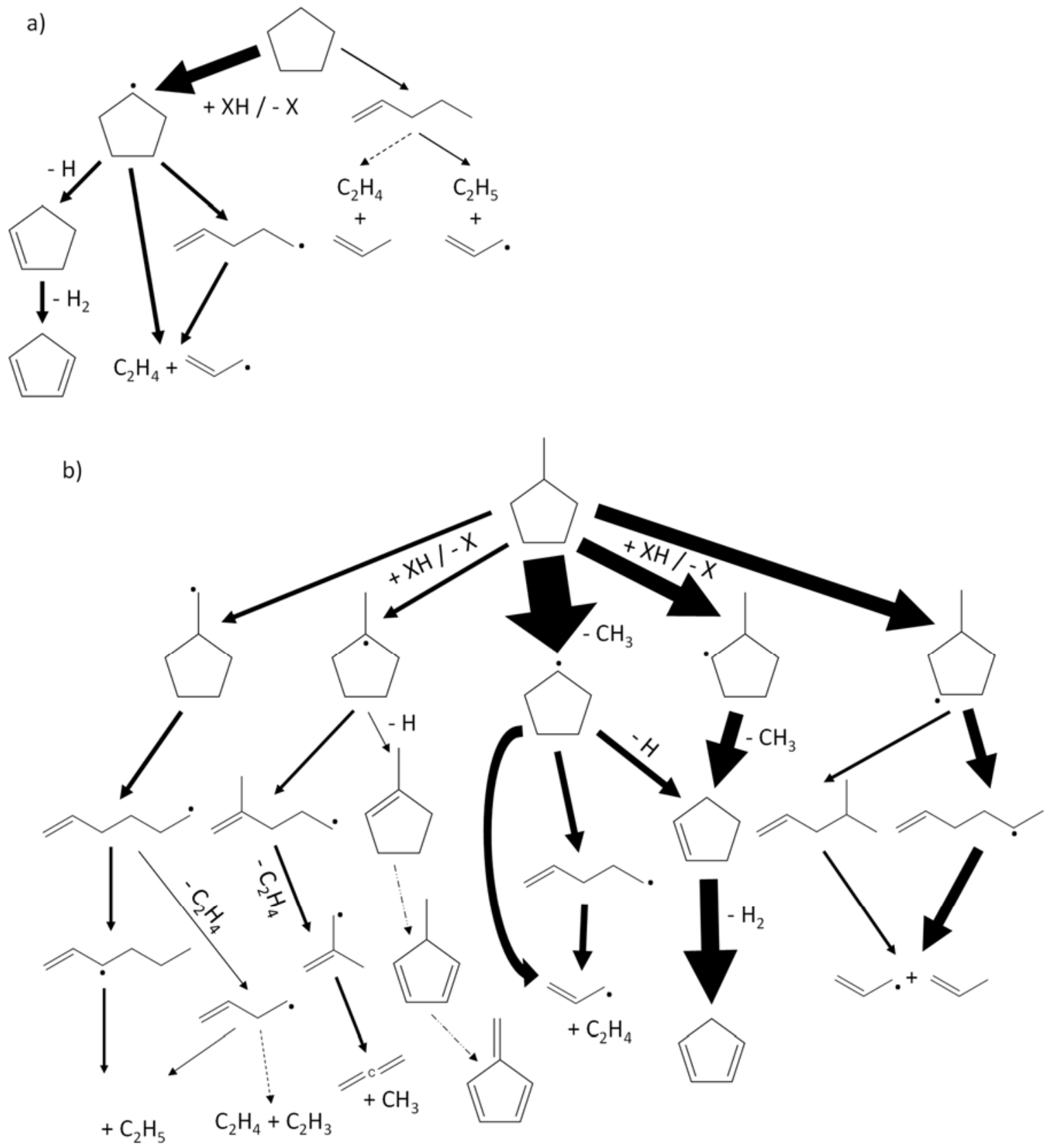

Figure 9: Reaction pathway analysis of the oxidation of a) cyclopentane and b) methylcyclopentane in a JSR at $\mathrm{T}=1150 \mathrm{~K}, \mathrm{p}=1 \mathrm{~atm}, \tau=0.07 \mathrm{~s}$, and $\varphi=1$ (the size of the arrows is proportional to the flow rate).

Figure 9a depicts the reaction pathway analysis performed under stoichiometric conditions, at atmospheric pressure and $1150 \mathrm{~K}$ (the temperature at which ca. $45 \%$ of the fuel is consumed) 
of the oxidation of cyclopentane. Under these conditions, the oxidation of cyclopentane is quite simple: $87.3 \%$ of cyclopentane yields cyclopentyl radicals $(\mathrm{H}: 57.3 \%, \mathrm{OH}: 18.5 \%$, O: $6.5 \%$, $\mathrm{CH}_{3}: 3.1 \%$, a- $\mathrm{C}_{3} \mathrm{H}_{5}: 1.9 \%$ ) which in turn undergo a $\mathrm{C}-\mathrm{H} \beta$-scission $(32.5 \%)$ yielding cyclopentene, or two C-C $\beta$-scissions producing either pent-1-en-5-yl (30.7\%) or directly ethylene and allyl (36.4\%). According to our mechanism, $99.8 \%$ of pent-1-en-5-yl gives ethylene and allyl radicals while $85.2 \%$ of cyclopentene loses $\mathrm{H}_{2}$ and yields cyclopentadiene. Under these conditions, pent-1-ene unimolecularly decomposes into ethyl and allyl radicals (81 $\%)$ or ethylene and propene $(11.3 \%)$. Hydrogen is the most important radical as far as cyclopentane consumption is concerned. These $\mathrm{H}$ atoms are mostly produced by $\mathrm{C}-\mathrm{H} \beta-$ scissions from allyl (37.8 \%), cyclopentyl (29.3\%), and ethyl radicals (11.3\%). Allyl is also a key radical in the oxidation of cyclopentane: $54.5 \%$ of the allyl produced gives allene after a hydrogen departure and $25 \%$ of allyl also produces propene by recombination with hydrogen atoms $(17.4 \%)$ or $\mathrm{H}$-abstraction reactions from $\mathrm{a}_{-} \mathrm{C}_{3} \mathrm{H}_{4}(4.8 \%)$ or cyclopentane $(2.8 \%)$. Finally, $5.6 \%$ of allyl recombines with methyl to give but-1-ene. As above-mentioned, benzene accumulation is well reproduced when cyclopentane is oxidized but under-estimated during methylcyclopentane oxidation. The reaction pathway analysis showed that ca. two third of the benzene proceeds from a reaction between a cyclopentadienyl radical and allene $(38.3 \%)$ or propyne $(29.0 \%)$ proposed by Wang et al. ${ }^{45}$ while the other third comes from the reaction of propargyl with itself either directly $(14.5 \%)$ or through the formation of linear $\mathrm{C}_{6} \mathrm{H}_{6}$ intermediates as proposed by Leung and Lindstedt ${ }^{49}$.

Methylcyclopentane oxidation pattern is much more complicated. Figure $9 \mathrm{~b}$ illustrates the reaction pathways analysis of methylcyclopentane under stoichiometric conditions, at atmospheric pressure and $1150 \mathrm{~K}$, the temperature at which ca. $60 \%$ of the fuel is consumed. Under these conditions, $27.6 \%$ of the fuel is consumed through the decomposition yielding methyl and cyclopentyl radicals. The other unimolecular decompositions producing 1- and 2hexene only account for few percentages ( $4.5 \%$ and $1.1 \%$ respectively) of the total flow rate. Other important pathways for fuel consumption are $\mathrm{H}$-abstraction reactions by $\mathrm{H}(36.7 \%), \mathrm{OH}$ $(14.8 \%)$, and $\mathrm{CH}_{3}(6.8 \%)$ yielding the four methylcyclopentyl radicals. Among these methylcyclopentyl radicals mcps1 is the most abundant $(24.7 \%)$, followed by mcps $2(22.5 \%)$ slightly less produced because of the difference in the rate constants of the H-abstraction by $\mathrm{OH}$ proposed by Sivaramakrishnan and Michael ${ }^{10}$, then mcpm $(7.3 \%)$ and mcpt $(7.2 \%)$ are produced in smaller quantities. Cyclopentyl radicals are consumed by ring opening $(67.2 \%)$ yielding pent-1-en-5-yl or allyl and ethylene. Cyclopentyl can also undergo $\mathrm{C}-\mathrm{H} \beta$-scissions $(32.2 \%)$ yielding cyclopentene $+\mathrm{H}$. Cyclopentene then produces cyclopentadiene by dehydrogenation $(82.5 \%)$, cyclopentenyl $(9.7 \%)$ or 1,3-pentadiene $(6.7 \%)$. Cyclopentene is mainly produced by $\mathrm{C}-\mathrm{C} \beta$-scission from mcps 1 (57.1\%) for which ring opening is a less minor channel $(33.6 \%)$. On the contrary, the other secondary methylcyclopentyl radical (mcps2) undergoes ring opening, mostly to form hex-1-en-5-yl (74.6\%). Finally, mcpm and mcpt are much less produced and participate to the production of $1,3-\mathrm{C}_{4} \mathrm{H}_{6}$, allene and fulvene. Almost three quarter of the benzene comes from the reaction of cyclopentadienyl and allene $(45.1 \%)$ or propyne $(27.6 \%)$ while ca. $16 \%$ comes from propargyl and less than $2 \%$ from fulvene. These pathways would probably need to be reconsidered on the light of theoretical calculations to better reproduce our experimental results.

\section{Conclusions}

The oxidation of cyclopentane and methylcyclopentane was studied in a jet-stirred reactor at atmospheric pressure, a residence time of $70 \mathrm{~ms}$ and for various equivalence ratios $(\varphi=0.5$, 1, and 2). A detailed kinetic mechanism was developed in this work based on our previous studies which is well able to reproduce our experimental results in JSR although the formation of benzene needs to be revisited in the case of methylcyclopentane. Thanks to this mechanism, 
the main consumption pathways for the oxidation of cyclopentane and methylcyclopentane under our experimental conditions were identified. It was found that methylcyclopentane was more reactive, under these conditions, than cyclopentane mostly because of the initiation step producing cyclopentyl and methyl radicals. In both systems, cyclopentyl and allyl are key intermediates as far as radicals are concerned while cyclopentene and cyclopentadiene are key intermediates among the stable species. However, experimental data under higher pressures and in different set-ups would be of importance to fully validate our detailed kinetic mechanism.

\section{References}

1. Serinyel, Z.; Herbinet, O.; Frottier, O.; Dirrenberger, P.; Warth, V.; Glaude, P. A.; Battin-Leclerc, F. Combustion and Flame 2013, 160, 2319-2332.

2. Tsang, W. International Journal of Chemical Kinetics 1978, 10, 599-617.

3. Sirjean, B.; Buda, F.; Hakka, H.; Glaude, P. A.; Fournet, R.; Warth, V.; Battin-Leclerc, F.; Ruiz-Lopez, M. Proceedings of the Combustion Institute 2007, 31 I, 277-284.

4. Daley, S. M.; Berkowitz, A. M.; Oehlschlaeger, M. A. International Journal of Chemical Kinetics 2008, 40, 624-634.

5. Al Rashidi, M. J.; Thion, S.; Togbé, C.; Dayma, G.; Mehl, M.; Dagaut, P.; Pitz, W. J.; Zádor, J.; Sarathy, S. M. Proceedings of the Combustion Institute 2017, 36, 469-477.

6. Al Rashidi, M. J.; Mehl, M.; Pitz, W. J.; Mohamed, S.; Sarathy, S. M. Combustion and Flame 2017, 183, 358-371.

7. Al Rashidi, M. J.; Mármol, J. C.; Banyon, C.; Sajid, M. B.; Mehl, M.; Pitz, W. J.; Mohamed, S.; Alfazazi, A.; Lu, T.; Curran, H. J.; Farooq, A.; Sarathy, S. M. Combustion and Flame 2017, 183, 372-385.

8. $\quad$ Burgoyne, J. H.; Silk, J. A. Journal of the Chemical Society (Resumed) 1951, 572-584.

9. Brown, T. C.; King, K. D. International Journal of Chemical Kinetics 1989, 21, 251-266.

10. Sivaramakrishnan, R.; Michael, J. V. Combustion and Flame 2009, 156, 1126-1134.

11. Sirjean, B.; Glaude, P. A.; Ruiz-Lopèz, M. F.; Fournet, R. The Journal of Physical Chemistry A 2008, $112,11598-11610$.

12. Yang, Y.; Boehman, A. L. Combustion and Flame 2010, 157, 495-505.

13. Yang, Y.; Boehman, A. L.; Simmie, J. M. Combustion and Flame 2010, 157, 2369-2379.

14. Yang, Y.; Boehman, A. L.; Simmie, J. M. Combustion and Flame 2010, 157, 2357-2368.

15. Tian, Z.; Tang, C.; Zhang, Y.; Zhang, J.; Huang, Z. Energy \& Fuels 2015, 29, 428-441.

16. Fridlyand, A.; Goldsborough, S. S.; Al Rashidi, M.; Sarathy, S. M.; Mehl, M.; Pitz, W. J. Combustion and Flame 2019, 200, 387-404.

17. Le Cong, T.; Dagaut, P.; Dayma, G. Journal of Engineering for Gas Turbines and Power-Transactions of the Asme 2008, 130.

18. Dagaut, P.; Cathonnet, M.; Rouan, J. P.; Foulatier, R.; Quilgars, A.; Boettner, J. C.; Gaillard, F.; James, H. Journal of Physics E: Scientific Instruments 2000, 19, 207-209.

19. Fenard, Y.; Dagaut, P.; Dayma, G.; Halter, F.; Foucher, F. Proceedings of the Combustion Institute 2015, $35,317-324$.

20. Fenard, Y.; Dayma, G.; Halter, F.; Foucher, F.; Serinyel, Z.; Dagaut, P. Energy \& Fuels 2015, 29, 11071118.

21. Muller, C.; Michel, V.; Scacchi, G.; Côme, G. M. Journal de Chimie Physique 1995, 92, 1154-1178.

22. Glarborg, P.; Kee, R. J.; Grcar, J. F.; Miller, J. A.: Sandia National Laboratories, Livermore, CA (USA), 1986.

23. Lutz, A. E.; Kee, R. J.; Miller, J. A.: Sandia National Laboratories, Livermore, CA (USA), 1988.

24. Sirjean, B.; Glaude, P. A.; Ruiz-Lopez, M. F.; Fournet, R. The Journal of Physical Chemistry A 2006, $110,12693-12704$.

25. Gong, C.-M.; Li, Z.-R.; Li, X.-Y. Energy \& Fuels 2012, 26, 2811-2820.

26. Zhang, F.; Wang, Z.; Wang, Z.; Zhang, L.; Li, Y.; Qi, F. Energy \& Fuels 2013, 27, 1679-1687.

27. Handford-Styring, S. M.; Walker, R. W. Physical Chemistry Chemical Physics 2002, 4, 620-627.

28. Handford-Styring, S. M.; Walker, R. W. Journal of the Chemical Society, Faraday Transactions 1995, 91, $1431-1438$.

29. Dayma, G.; Thion, S.; Lailliau, M.; Serinyel, Z.; Dagaut, P.; Sirjean, B.; Fournet, R. Proceedings of the Combustion Institute 2019, 37, 429-436.

30. Sivaramakrishnan, R.; Michael, J. V.; Ruscic, B. International Journal of Chemical Kinetics 2012, 44, 194-205.

31. Buda, F.; Bounaceur, R.; Warth, V.; Glaude, P. A.; Fournet, R.; Battin-Leclerc, F. Combustion and Flame 2005, 142, 170-186. 
32. Dayma, G.; Halter, F.; Foucher, F.; Togbé, C.; Mounaim-Rousselle, C.; Dagaut, P. Energy \& Fuels 2012, $26,4735-4748$.

33. Dayma, G.; Togbé, C.; Dagaut, P. Energy \& Fuels 2011, 25, 4986-4998.

34. Tsang, W. Journal of Physical Chemistry A 2006, 110, 8501-8509.

35. Manion, J. A.; Awan, I. A. International Journal of Chemical Kinetics 2018, 50, 225-242.

36. Sun, Y.; Zhou, C.-W.; Somers, K. P.; Curran, H. J. The Journal of Physical Chemistry A 2020.

37. Battin-Leclerc, F. Progress in Energy and Combustion Science 2008, 34, 440-498.

38. Herbinet, O.; Rodriguez, A.; Husson, B.; Battin-Leclerc, F.; Wang, Z.; Cheng, Z.; Qi, F. The Journal of Physical Chemistry A 2016, 120, 668-682.

39. Sharma, S.; Green, W. H. The Journal of Physical Chemistry A 2009, 113, 8871-8882.

40. Jin, H.; Frassoldati, A.; Wang, Y.; Zhang, X.; Zeng, M.; Li, Y.; Qi, F.; Cuoci, A.; Faravelli, T. Combustion and Flame 2015, 162, 1692-1711.

41. Yang, J.; Zhao, L.; Yuan, W.; Qi, F.; Li, Y. Proceedings of the Combustion Institute 2015, 35, 855-862.

42. Dagaut, P.; Ristori, A.; Frassoldati, A.; Faravelli, T.; Dayma, G.; Ranzi, E. Energy \& Fuels 2013, 27, 1576-1585.

43. Zhong, X.; Bozzelli, J. W. The Journal of Physical Chemistry A 1998, 102, 3537-3555.

44. Zhong, X.; Bozzelli, J. W. International Journal of Chemical Kinetics 1997, 29, 893-913.

45. Wang, H.; Liu, Z.; Gong, S.; Liu, Y.; Wang, L.; Zhang, X.; Liu, G. Combustion and Flame 2020, 212 , 189-204.

46. Oleinikov, A. D.; Azyazov, V. N.; Mebel, A. M. Combustion and Flame 2018, 191, 309-319.

47. Ghildina, A. R.; Oleinikov, A. D.; Azyazov, V. N.; Mebel, A. M. Combustion and Flame 2017, 183, 181 -

193.

48. Vermeire, F. H.; De Bruycker, R.; Herbinet, O.; Carstensen, H.-H.; Battin-Leclerc, F.; Marin, G. B.; Van Geem, K. M. Fuel 2017, 208, 779-790.

49. Leung, K. M.; Lindstedt, R. P. Combustion and Flame 1995, 102, 129-160. 